\title{
THE EFFECTS OF COGNITIVE TRAINING ON EXECUTIVE FUNCTIONS AND READING IN TYPICALLY DEVELOPING CHILDREN WITH VARIED SOCIOECONOMIC STATUS IN BRAZIL
}

\author{
Janaina Weissheimer ${ }^{1^{*}}$ \\ Renata Callipo Fujii ${ }^{1 \times *}$ \\ Juliana Geizy Marques de Souza ${ }^{1 * *}$ \\ ${ }^{1}$ Universidade Federal do Rio Grande do Norte, Natal, RN, Brasil
}

\begin{abstract}
Recent findings show that children from low-socioeconomic status (SES) tend to have reduced performance on several tasks involving working memory, attention and executive control. In addition, researchers argue for the effectiveness of training of these same cognitive skills as a way to ameliorate children's EF skills as well as scholastic outcomes. To investigate possible training effects and to study the impact of SES on scholastic achievement in Brazilian children, we trained 61 children for 5-7 weeks and compared their performance with that of 60 age-matched peers on measures of executive functions and reading. Our results demonstrate a general effect of SES for the dependent variables. Furthermore, our findings demonstrate a positive near transfer effect on a working memory and a selective attention test and a far transfer effect on the words and pseudowords reading measure.

Key-words: Executive Functions; Socioeconomic status; Reading; Cognitive Training.
\end{abstract}

\footnotetext{
Possui graduação em Letras Português-Inglês, mestrado em Linguística Aplicada e doutorado em Letras pela Universidade Federal de Santa Catarina (2007). Realizou estágio pós-doutoral no Kutas Cognitive Lab na University of California San Diego (UCSD). É professora do Departamento de Línguas e Literaturas Estrangeiras Modernas da Universidade Federal do Rio Grande do Norte (UFRN) em Natal, membro permanente do Programa de Pós-Graduação em Estudos da Linguagem (PPGEL-UFRN), atuando na linha de pesquisa sobre Ensino e Aprendizagem de Línguas Estrangeiras, e colaboradora no Instituto do Cérebro da UFRN. Tem experiencia na área de Psicolinguística, com ênfase em Aprendizagem de Inglês como L2. Seu e-mail é: janaina. weissheimer@gmail.com. ORCID: https://orcid.org/0000-0002-6318-4906

${ }^{* *}$ Possui especialização em Ensino-Aprendizagem de Inglês como Língua Estrangeira e Mestrado em Estudos da Linguagem (UFRN). Atualmente é Doutoranda em Estudos da Linguagem e atua em colaboração com o Working Memory and Plastictiy Laboratory (University of California, Irvine - School of Education). Também desenvolve pesquisa em colaboração com o Haskins Laboratories (YALE University) - apoio da Coordenação de Aperfeiçoamento de Pessoal de Nível Superior - Brasil (CAPES) - Código de Financiamento 001. Seu e-mail é: renatacallipofj@gmail.com. ORCID: https://orcid.org/0000-0001-5355-9068.

${ }^{* * *}$ Graduada em Letras Língua Inglesa e Literaturas pela Universidade Federal do Rio Grande do Norte (UFRN), realizou estágio de garduação na Troy University no Alabama (EUA) com bolsa do Programa Letras sem Fronteiras e é atualmente bolsista de mestrado do Programa de Pós-Graduação em Estudos da Linguagem da UFRN. Seu e-mail é julianamrqs0@gmail.com. ORCID: https://orcid.org/0000-0002-4612-7520.
} 


\section{Introduction}

Translational studies have become more common in the last few decades (Varma, Mccandliss \& Schwartz, 2008; Sigman, Peña, Goldin \& Ribeiro, 2014;Bowers, 2016; Dresler, Bugden, Gouet, Lallier, Oliveira, Pinheiro-Chagas, Pires, Wang, Zugarramurdi, \& Weissheimer, 2018). The main motivation for conducting these studies is to inspire evidence-based education through the bridging of sound research findings and educational practices. Research in Psycholinguistics and Neurocognition in Brazil has also been consistently following this trend (Maia 2018; Lent, Buchweitz \& Mota, 2018), and evidence from several scientific investigations has informed different pedagogical interventions nationwide.

One specific question which has received much attention recently is how brain development and cognitive functions are influenced by a complex interplay between genetic and environmental factors, with Socioeconomic Status - SES as one of the key variables representing the environment (Noble, McCandliss \& Farah, 2007).

With that in mind, the purpose of our study ${ }^{1}$ was to examine whether children from low and high SES might differentially benefit from the training of EFs skills; and if improved performance is transferable to novel, untrained tasks such as reading performance. To do so, the following research questions were asked: a) Can intervention on basic EF skills have a positive effect on the development of similar cognitive skills (near transfer)? b) Can intervention impact non-trained reading skills (far transfer)?; c) Will training impact children from high SES and low SES in a different manner? To achieve our goals, we implemented an inschool cognitive intervention, consisting of 10 training sessions that took place over the course of 5-7 weeks, which will be described in the following section.

\section{Literature review}

SES is a multidimensional construct and refers to an individual's access to economic and social resources, together with the social positioning, benefits, prestige and power that stem from these resources (Brito \& Noble, 2014; Duncan \& Magnuson, 2012; Hackman \& Farah, 2009).

It has been argued that SES is highly predictive for cognitive development especially in the domain of language and executive functions, and it is associated with scholastic achievement (Lipina, Martelli \& Colombo, 2005; Noble, Norman \& Farah, 2005; Farah , Shera, Savage, Giannetta, Malmud \& Hurt, 2006; Noble et al., 2007; Hackman \& Farah, 2009; Duncan \& Magnuson, 2012; Brito \& Noble, 2014; Hsu, Novick \& Jaeggi, 2014).

Several studies suggest that low-SES children perform generally worse in cognitive tasks when compared to middle SES children (Noble et al., 2005; Farah et al., 2006), which is especially apparent in tasks that rely on prefrontal/executive systems. For example, Lipina et al. (2005) used a delayed-response paradigm task 
to evaluate the processes of working memory and inhibitory control in low and middle SES infants. Results showed that children from low-SES background had lower scores in both accuracy and speed on measures of executive attention and alerting. This indicates that SES seems to modulate response conflict and inhibition of distracting information already at an early age. John, Kibbe \& Tarullo (2019) assessed children aged 4.5 - 5.5 years old. In this study, children completed a working memory task involving a cognitive load component and a go/no go task in order to assess vigilance and inhibitory control. Results showed that children from low SES backgrounds had lower accuracy scores for working memory skills, inhibitory control and vigilance; as well as a slower reaction time for working memory.

Executive functions (EF), in turn, refer to a set of skills which are indispensable for mental and physical health; school readiness and success; psychological, social and cognitive development. EFs play an important role in complex cognition and are essential mental processes needed for reasoning, planning, problem solving, memory and language processing (Diamond, 2013). In the EFs literature, there are three more prevailing basic EFs: updating, inhibition and shifting. (Hofmann, Schmeichel \& Baddeley, 2012; Miyake, Friedman, Emerson, Witzki, Howerter \& Wager, 2000).

Updating involves the ability to keep information in mind in an active state, in such a way that it is quickly retrievable; in other words, being able to process information while holding it in mind (Baddeley \& Hitch, 1994; Diamond, 2013; Hofmann et al., 2012). Updating is intimately associated with the construct of working memory. Inhibition involves the ability to "deliberately inhibit dominant, automatic, or prepotent responses when necessary" (Miyake et al., 2000, p.57). Finally, Shifting, also referred to as 'attention switching' or 'task switching', concerns the ability to shift back and forth between multiple tasks, mental sets or operations (Monsell, 2003).

Impairments in EFs are closely linked to inattentive behavior and forgetting; high levels of distractibility; difficulties in monitoring classroom work; and difficulties in generating new solutions to problems (Alloway, Gathercole, Kirkwood \& Elliot, 2008). Children with deficits in EF skills usually present an extremely high risk of making poor academic progress and usually struggle in learning measures (vocabulary, reading and math).

Although regular schooling improves EF skills, accumulating evidence has been showing that targeted cognitive interventions can also have an effect on EFs (Chein \& Morrison, 2010; Jaeggi, Buschkuehl, Jonides, \& Perrig, 2008). These interventions are usually referred to as brain training or cognitive training and are intended to improve the function of one or more basic cognitive processes, such as vision, hearing, memory, attention, decision-making or motor control (Pahor, Jaeggi \& Seitz, 2018).

For example, Goldin et al. (2014) conducted a study with one-hundred and eleven typically developing 6-year-olds on an experimental and an active control group of low-SES children. Computerized games were used in a pretest-trainingposttest design for the duration of three months. The intervention aimed at investigating whether the training related-benefits would elicit far transfer to real-life situations. Results suggest transfer to some facets of executive function 
and improvement in scholastic outcomes based on assessments by teachers. Most importantly, the intervention had an effect on equalizing academic outcomes across children who had lower attendance in school.

Despite being encouraging, these findings on transfer effects are often small and not consistent across studies. Furthermore, training studies usually show neartransfer effects; however, when it comes to far-transfer effects, the picture is a lot less clear. Last but not least, training studies usually focus on $\mathrm{WEIRD}^{2}$ populations, and theygenerally do not include SES as a potentially moderating factor.

Potential outcomes from this study could be that: a) training can be especially beneficial for the low SES children because they have room to improve; or b) training could benefit the high SES kids more, showing the well-known Matthew effect (the rich get richer).

In Brazil, more than 15.2 million people live in extreme poverty (IBGE, 2018), and this number has escalated in the past four years. Although there are a few curriculum-based interventions, to the best of our knowledge, there are no game-like effective programs that include EFs training designed for public school children. Therefore, understanding the impact of SES and EFs training on scholastic outcomes can help ameliorate the achievement gap in Brazilian children.

\section{Methods}

\section{1 Context and Participants}

Participants were 121 typically-developing children, ranging in age from 8 to 10 years old. Children were recruited from 7 classrooms in two schools one private (high-SES) and one public (low-SES) - in the city of Natal, Brazil (see Table 1 for demographic data). In general, the private school in this study serves families from high-income backgrounds; whereas the public school serves families from low-income backgrounds ${ }^{3}$. Parental education and occupation varied widely throughout the sample; though, in general, higher levels of education and salaries were associated with the private school context, and lower levels of education and salaries were associated with the public-school context. Children who could not read or write did not take part in the study; and children who were older than 10 years old did not participate either. ${ }^{4}$

Table 1: Demographic Data

\begin{tabular}{|l|l|l|}
\hline Demographic information & $\begin{array}{l}\text { Public } \\
\text { School } \\
\text { (low SES) }\end{array}$ & $\begin{array}{l}\text { Private School } \\
\text { (high SES) }\end{array}$ \\
\hline $\mathrm{N}$ & 66 & 57 \\
\hline Number of girls (\%) & $33(50)$ & $30(53)$ \\
\hline Third/Fourth graders (\%) & $53 / 47$ & $51 / 47$ \\
\hline Parent education (\% high school completion) & 17 & 88 \\
\hline Receives government support (\%) & 41 & 0 \\
\hline Own home appliances $\left.{ }^{*} \%\right)$ & 17 & 85 \\
\hline
\end{tabular}




\begin{tabular}{|l|l|l|}
\hline Completed training (\%) & 66 & 91 \\
\hline
\end{tabular}

${ }^{*} \mathrm{TV}$, computer, microwave.

Before the testing and the intervention phases, parents signed the consent forms approved by the Ethics Committee (Approval no. 2.052.853), and the principals from both schools signed a compliance statement stating that the research could be carried out in the selected third and fourth grade classrooms. A meeting with parents, school coordinators, and teachers was also conducted at the schools; the researchers explained the goals of the study and parents were able to ask questions, prior to reading and signing the consent forms.

\subsection{Instruments and procedures}

The study consisted of pre-testing, intervention (10 training sessions, which lasted approximately 20 - 25 minutes each), posttesting and follow-up sessions (to assess long term retention effects three months after the posttest phase ${ }^{5}$ ). Students from both private and public schools were randomly assigned to one of two conditions: active control or experimental group. Both groups were submitted to the same sets of pretesting and post testing tasks. ${ }^{6}$ However, during the intervention, the experimental group trained on individual Android tablets by playing games which specifically targeted EF skills (such as shifting, inhibition and updating), while the active control group trained on individual tablets by playing games that only minimally involved EF control - spotting differences between two images and counting dots (Au, J., Jaeggi, S. M., \& Buschkuehl, M. 2018).

The pre and posttest games as well as the training games used in both conditions (experimental and active control) were tailored specifically for the age range and designed to be engaging. ${ }^{7}$ All games incorporate video game-like features and/or artistic graphics. For example, while playing, children earned gold coins for correct answers, advanced to more difficult and complex levels, were rewarded with bonus points and bonus rounds and unlocked different images (including superheroes, funny animals and insects, and other attractive themes).

\subsubsection{Tablet Games}

\section{Training Games}

During the intervention, the experimental group played two games in each of the training sessions: a) Match Quest (a variant of an n-back task); and b) Recall All (a variant of a complex span task). These games were developed specifically to tax EFs. To play these games successfully children must store and process information, activate their updating skills, and work on their interference resolution skills as the trials are familiar but distracting.

In Match Quest, children were presented with a series of images one at a time (e.g. shoes, toys, fruits, animals, insects, and superheroes). They were required to touch the image if the image was the same as the one presented $n$ trials before 
where $n$ was a variable that adaptively moved up or down in accordance with the subject's performance. In this game, $30 \%$ of the trials consisted of targets, whereas other $30 \%$ consisted of lure trials, i.e., stimuli that appeared $n \pm 1$ or $n \pm 2$ trials ago (=trials that were familiar but distracting).

For the Recall All Game (Ramani, G. B., Jaeggi, S. M., Daubert, E. N., \& Buschkuehl, M., 2017), children were presented with a series of characters (e.g., a clownfish, a pirate, a frog or an alien) tied to a background story (e.g., a coral reef, a pirate ship, a magical pond or outer space). Each character was presented either right-side up or upside-down, and children were asked to indicate the orientation of the character by pressing the appropriate button on the tablet. In addition, they were instructed to remember the color of the character, and they were required to reproduce the order of the colors representing the sequence at the end of the trial. The task was also adaptive in that the sequence increased in size as a function of the children's performance.

The active control group also played two games in each of the training sessions. a) Eagle Eye, and b) Clouds. Eagle Eye required participants to find differences between two pictures presented on the tablet. The game also got progressively harder in that the pictures got more complex and there were more differences over the course of the training sessions.

Clouds required participants to compare two 'clouds' of stimuli (e.g. dots) on the screen and to tap on the one that contained more stimuli as quickly as possible. The task was also adaptive in that the density and ratio between clouds varied depending on participants' performance.

The training sessions took place over the course of approximately 5 to 7 weeks depending on the number of classes each group had during that period (some took longer because of the interruption of classes caused by holidays, field trips, teacher's meetings).

\section{Pre and Posttest Assessments}

To assess training outcomes, we administered a battery of tasks to assess working memory (near transfer), inhibitory control (near transfer), as well as reading-related functions (far transfer).

Working memory:

$\mathrm{N}$-back. We used a non-trained spatial version of the task as an outcome measure, also played on a tablet. Other than the training task, the outcome measure was not adaptive, that is, children completed 1-back and 2-back levels. The dependent variable was the proportion of hits minus the proportion of false alarms.

Spatial Span, a tablet-based version of the corsi blocks task (forwards and backwards) was used to assess spatial working memory. The number of correct trials for both forward and backward versions served as dependent variable.

Inhibitory control:

Dogs and Monkeys.I n this tablet-based game, participants were presented with pictures of dogs or monkeys on either the right or left side of the screen. They were required to touch a button on the same side when seeing the picture of 
the dog, and a button on the opposite side when seeing the picture of a monkey. The dependent variables used here were reaction time (correct responses) where the rule shifted (e.g. from dog to monkey or vice versa; switch trials) as well as the difference in reaction time between the incongruent (monkey) and congruent $(\operatorname{dog})$ trials.

d2 test (Brickenkamp, 2002). This test aims at measuring processing speed and inhibitory control while processing a series of similar visual stimuli. Participants were presented with a series of $\mathrm{p}$ and $\mathrm{d}$ with several dashes, and they were required to mark all letters $\mathrm{d}$ with two dashes as quickly as possible while ignoring distractors. Here, we used CP - "Concentration Performance" (CP is derived from the number of the correctly crossed out relevant items - "d" with two dashes minus the errors of commission (E2) as dependent variable. CP is normally distributed, it is highly reliable and provides an excellent index of the coordination of speed and accuracy of performance.

Reading:

These tasks were administered to assessed children's reading abilities. The tasks were the following: a) reading speed and comprehension; b) words and pseudowords.

For the Reading Speed and Comprehension Task four different expository texts were used (Saraiva, Moojen, Munarski, 2007): for the third graders - "O Camaleão" ( 85 words) and "Bebê Elefante" ( 92 words); and for the fourth graders - "A Girafa" (172 words) and "As Lhamas" (140 words). The ones selected were applied to gather information about silent reading speed, reading out loud speed and reading comprehension skills. In individual sessions, the examiner told each participant that they were going to silently read a text and that they should pay close attention because they would have to answer some questions about what they had read. Silent reading time was recorded and, following that, students were asked to a) retell the story; b) answer the questions about the text; and finally c) read the text aloud (this was also timed, and participants were scored according to the number of words read/minute).

For the Words and Pseudowords Task (Salles, 2005) children read a list of 60 words and pseudowords. They were instructed to read as fast as they could, but slowly enough so they would pronounce each word clearly and correctly. They were also informed that some words from the list did not exist in their mother tongue - they were 'made up words' -; but, in spite of that, they could still be read just like 'real words'.

The first part of the assessment sessions(d2) was conducted in a group setting (all the students in the same classroom). The tablet games (N-Back,Touch Base and Dogs and Monkeys) were administered in a smaller group setting (5 - 6 students). The paper and pencil tasks (reading comprehension, reading aloud and words/ pseudowords test) were carried out in individual sessions. The research assistants administering the reading measures were blind to the training condition. 


\subsection{Data analyses procedures}

We first ran the Shapiro-Wilk normality test, which showed that overall our sample was normally distributed. We then implemented a 2 school (private vs. public) $\mathrm{x}$ group (experimental vs. control) $\mathrm{x}$ time(pre vs. posttest) experimental design and ran repeated measures ANOVAs, in which school and group were entered as between group factors, and time was considered a within group factor. A Tukey post-hoc test was applied to correct the significant $p$-values that resulted from the ANOVA tests.

To conduct our analyses, we used JASP Team (2018), version 0.9. Specifically, we report the probability of our data fitting the null versus the alternative hypothesis, setting the confidence interval at $95 \%$ and $p$-value significance at 0.05 .

\section{Results and discussion}

Descriptive data for all assessment sessions and groups are provided in Tables 2 and 3, together with the respective effect sizes. Moderate and large effect sizes are highlighted in bold.

Table 2. Descriptive data and effect sizes for the experimental group

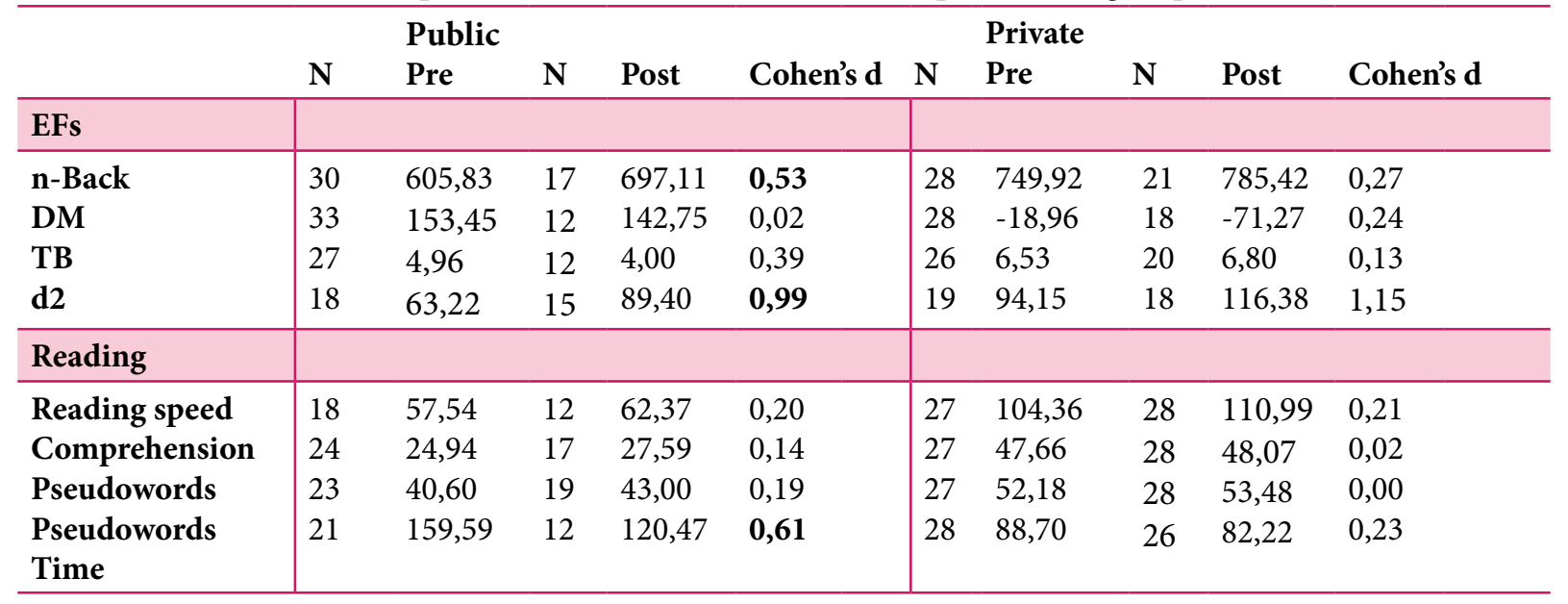

Table 3. Descriptive data and effect sizes for the control group

\begin{tabular}{|c|c|c|c|c|c|c|c|c|c|c|}
\hline & \multicolumn{3}{|c|}{ Public } & \multicolumn{7}{|c|}{ Private } \\
\hline & $\mathbf{N}$ & Pre & $\mathbf{N}$ & Post & Cohen's d & $\mathbf{N}$ & Pre & $\mathbf{N}$ & Post & Cohen's d \\
\hline \multicolumn{11}{|l|}{ EFs } \\
\hline n-Back & 31 & 657,64 & 19 & 513,26 & 1,10 & 27 & 774,11 & 24 & 771,37 & 0,02 \\
\hline DM & 32 & $-17,78$ & 14 & $-279,71$ & 0,35 & 27 & 38,25 & 20 & $-6,80$ & 0,19 \\
\hline TB & 31 & 5,83 & 12 & 4,33 & 0,55 & 26 & 6,61 & 21 & 5,23 & 0,55 \\
\hline d2 & 19 & 52,26 & 16 & 67,87 & 0,42 & 19 & 97,10 & 19 & 124,10 & 1,39 \\
\hline \multicolumn{11}{|l|}{ Reading } \\
\hline Reading speed & 24 & 63,17 & 20 & 65,05 & 0,05 & 28 & 110,39 & 28 & 114,09 & 0,13 \\
\hline Comprehension & 28 & 26,52 & 22 & 33,90 & 0,30 & 28 & 44,73 & 28 & 49,98 & 0,23 \\
\hline Pseudowords & 29 & 40,41 & 24 & 44,33 & 0,42 & 28 & 53,03 & 28 & 54,89 & 0,44 \\
\hline $\begin{array}{l}\text { Pseudowords } \\
\text { Time }\end{array}$ & 27 & 144,76 & 20 & 133,18 & 0,22 & 28 & 80,28 & 27 & 80,85 & 0,01 \\
\hline
\end{tabular}


In the remaining of this section, we will address the first two research questions separately, providing the results from the inferential tests and discussing them based on the literature reviewed. The issue of SES, the focus of our third research question, will be dealt with together with the answers to the first two questions.

\subsection{Near transfer effects and SES}

In respect to changes in children's EFs as a result of cognitive training in the same skills, an effect was found for the N-back test for children in the public school, as can be depicted from Figure 1a. The within-subjects analysis revealed that the changes displayed in Figure 1a were significant from baseline to posttest for N-Back scores in the case of the public school $(F(1,64)=4.373 p$ $=0.040)$. Between-subject repeated measures ANOVA also showed a significant interaction between school and group effects for this measure, indicating that the benefits of training were higher for children in the experimental group and in the public schools $(F(1,55)=6.865 p=0.011)$.

To recapitulate, the N-back test tackles the updating feature of working memory and measures the child's ability to indicate whether stimuli matched the ones presented $n$ trials before, where $n$ is a variable that adaptively moves up or down in accordance with the subject's performance. In other words, children are required to keep information in an active state while simultaneously adapting serial positions ' $n$ steps back' in a continuous stimulus stream.

Considering the $\mathrm{d} 2$ test of selective attention (Figure $1 \mathrm{~b}$ ), within-subject analyses showed that, in general, all children significantly improved in the $\mathrm{d} 2$ selective attention test from pretest to posttest $(F(2,120)=37.598 p=<0.001)$, regardless of what group (experimental and control) or school (public and private) they belonged to. Between-subjects repeated measures ANOVA analyses confirmed, still considering the $\mathrm{d} 2$ selective attention measure, that there was a significant interaction of group and school for this variable, with a training effect favoring the experimental group and the public $\operatorname{school}(F(2,120)=5.374 p=0.024)$.

As described in the Methods section, the $\mathrm{d} 2$ test is a timed test of selective and sustained attention and it allows us to assess children's attention and concentration performance. Attention is more directly related to the inhibition aspect of children's executive functioning, since it involves the ability to pay attention to specific relevant information while simultaneously inhibiting dominant, automatic, or prepotent responses when necessary (Miyake et al., 2000). Attention can also be, though more indirectly, related to shifting, which concerns the ability to shift attention back and forth between multiple tasks, mental sets or operations (Monsell, 2003).

Together, our findings of the effects of targeted cognitive training on EFs are in line with those of Zhang et al. (2018), which showed that children had pronounced gains in the trained working memory and inhibitory control tasks. What is more important to us, however, is the fact that such training impacted more effectively children of low-SES, who study in public schools in 
Brazil. In this sense, our findings are in line with those of Goldin et al. (2014), which also revealed transfer effects to some facets of executive function, among children of low-SES.

No significant changes were found in the within-subjects analyses from baseline to posttest for the other two EFs variables: DM test $(F(2,120)=0.278$ $p=0.600), \operatorname{TB}(F(2,120)=1.299 p=0.551)$ so we cannot make any claims or generalizations regarding training effects on these two measures (Figure $1 \mathrm{c}$ and 1d). However, between-groups analyses showed an interesting effect for the school factor considering these two tests. A DM between-groups school effect was found $(F(1,64)=5.009 p=0.029)$ with children in the private schools making fewer shifts than their peers in public schools from baseline to posttest. The same panorama was true for the TB measure, i.e., there was a between-groups school effect, with children in the private schools making fewer mistakes than their peers in public schools both in the forward $F(1,55)=8.008 p=0.006$ and backward conditions $F(1,55)=6.849 p=0.011$. These results point to the achievement gap between children in more and less privileged socioeconomic contexts in Brazil.

Figure 1. EFs performance across the two test sessions as a function of group and school

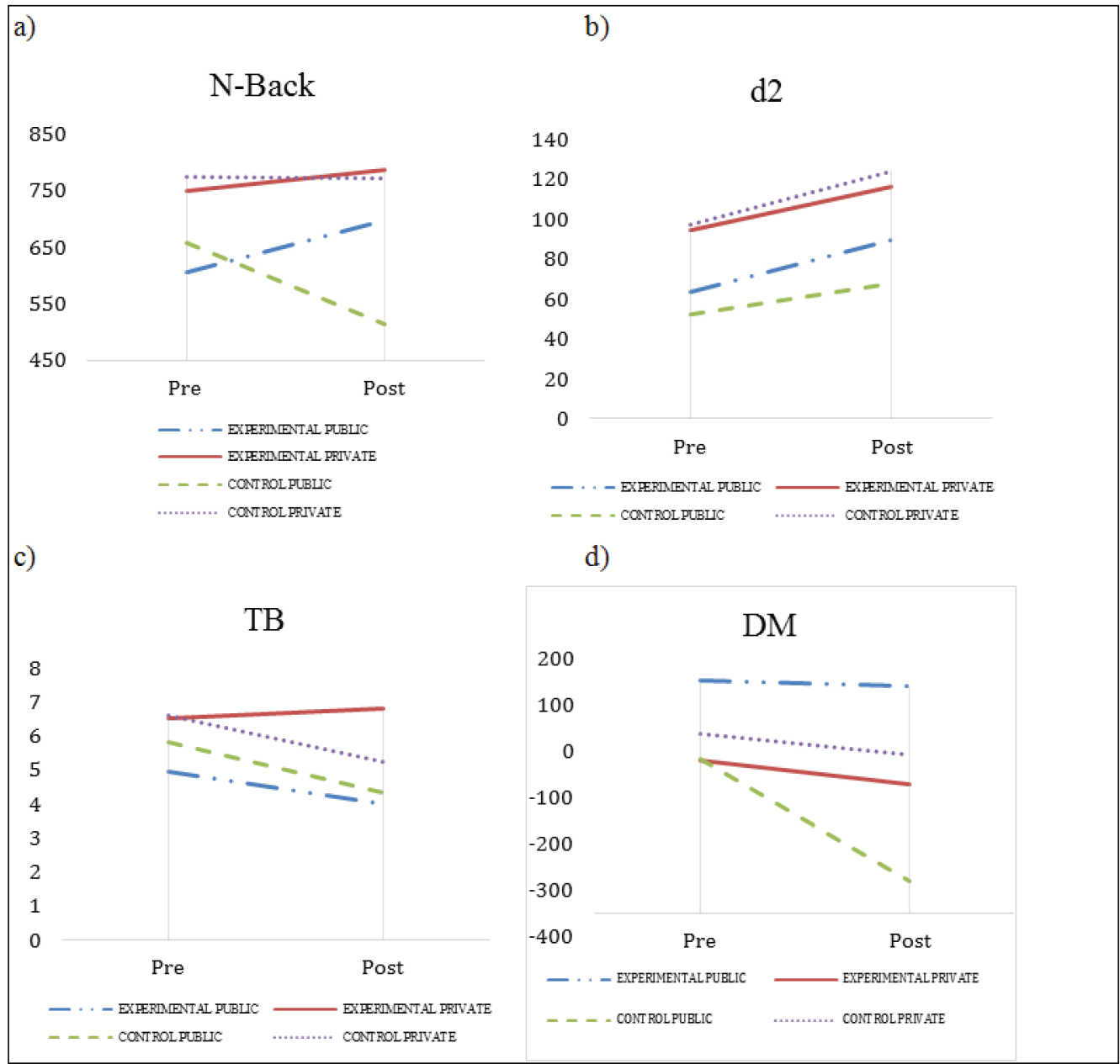


Overall, our results support studies of children ranging from preschool to middle school, which suggest that low-SES children have a reduced performance on several tasks when compared to middle and high SES children (Noble et al., 2005; Farah et al., 2006). In addition, our results are also in line with accumulating evidence that has been showing that targeted cognitive interventions can have a direct effect on EFs, such as vision, hearing, memory, attention, decision-making or motor control (Chein \& Morrison, 2010; Jaeggi et al., 2008; Pahor et al., 2018).

\subsection{Far transfer effects and SES}

Figure 2 shows that, similarly to what happened in the case of near transfer, a between-subjects school effect was found, this time for all the four measures of reading in our study: Reading speed $(F(1,120)=44.486 p=<.001)$, Comprehension $(F(1,120)=37.503 p=<.001)$, Pseudowords $(F(1,120)=48.172 p$ $=<.001)$ and Pseudowords Time $(F(1,120)=35.483 p=<.001)$. These data show that from baseline to posttest there were significant differences between groups, which can be attributed to their difference in SES.

These data seem to confirm the achievement gap assumption put forward by several researchers, according to which SES, cognitive ability and school achievement share a very strong relationship (Lipina et al., 2005; Noble et al., 2005; Farah et al., 2006; Noble et al., 2007; Hackman \& Farah, 2009; Duncan \& Magnuson, 2012; Brito \& Noble, 2014; Hsu \& Jaeggi, 2014), with children from low-SES contexts generally lagging behind when compared to their high-SES counterparts.

Considering the effects of training and SES together, the between-subjects repeated measures ANOVA used to test for immediate changes (pre vs. post) in non-trained reading skills revealed a main effect of group for one specific variable in our study - Pseudowords Time (Figure 2d), for children in the public school only, with children in the experimental group $(F(1,120)=6.022 p=0.029)$ significantly outperforming their peers in the control $\operatorname{group}(F(1,120)=1.588 p$ $=0.234)$. In the private school, however, no significant differences were found for the group factor (training vs. control), with children in both experimental $F(1,120)=45.358 p=<.001)$ and control $F(1,120)=49.331 p=<.001)$, with both groups improving in their Pseudowords Time scores.

We know from the vast science of reading literature that, when reading words that don't exist in their mother language (pseudowords, such as crafissoca or sanverca), but that could be real words, children are impelled to employ the phonological route in decoding, since such words cannot be otherwise accessed through their lexical route (Coltheart, 2013). In doing so, children go through grapho-phonological searches, which might take longer if these searches are not automatized. These mental computations share processes with working memory, since intermediate information about a word has to be maintained active while decoding processes are still under play. In that respect, our results show that low-SES children in the experimental group, after having received targeted EF 
training and, therefore, having become more efficient at skills that underlie decoding processes, were able to outperform children in the control group, who did not undergo such EFs training, in the speed at which they decoded words and pseudowords in the posttest.

To restate what has been discussed in the review of literature, the goal of cognitive training is to straighten brain systems that support effective performance on tasks that rely upon these underlying skills (Pahor et al., 2018). In this sense, it is expected that executive functions effects would generalize to untrained cognitive skills, such as reading. Because reading relies on general cognitive skills, mainly on the child's ability to simultaneously store and manipulate pieces of information, improvements in those basic cognitive skills may result in improvements in more complex skills, such as reading. In the case of our study, an improvement in the updating feature of working memory, measured here by the N-Back test, and also an improvement in selective attention, measured here by the $\mathrm{d} 2$ test (both reported in section 4.2), seem to have reflected on an improvement of graphophonological search efficiency, by the low-SES children under targeted cognitive training only, thus resulting in faster reading of words and pseudowords.

Figure 2: Reading performance across the two test sessions as a function of group and school

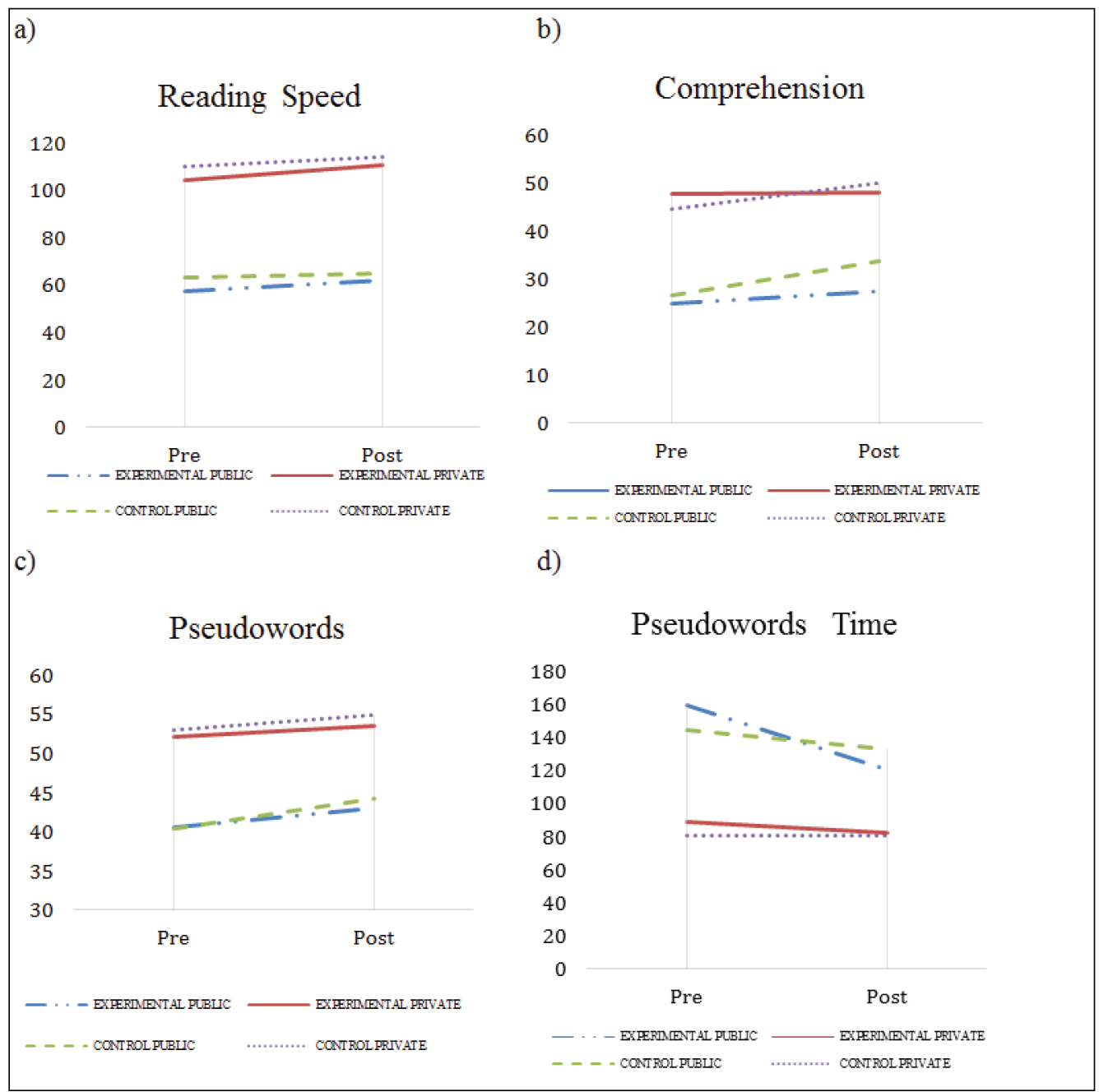


Notably, we believe that a crucial point to be made here is about the fact that specifically children of lower SES in our study were those who benefited more from the targeted EFs training, when compared to their peers trained in high SES private schools. The fact that these children in low SES public schools started reading (i.e. decoding words and pseudowords) faster from baseline to posttest in such a short period of time (5-7 weeks of training) encourages us to further advocate for such interventions as a way of mitigating the effects of the achievement gap these children in low SES contexts are often subjected to in Brazil.

\section{Conclusion}

The present study had the goal to investigate whether targeted training could lead to improvements in EFs and reading skills. We trained children for 5-7 weeks and we compared their performance to that of age-matched peers. Our results demonstrate thatan effect of school (private or public), which in our study is a marker of SES, was found for the EFs dependent variables in our study - N-Back, DM, TB and d 2 - and for the four reading measures applied - Reading speed, Comprehension, Pseudowords and Pseudowords Time. Furthermore, our findings corroborate earlier work demonstrating a positive effect of near-transfer in the case of EFs (measured by the N-Back test and the $\mathrm{d} 2$ selective attention test) and a positive effect of far-transfer on the speed at which children read words and pseudowords from the pre to the posttest.

Our results side with emerging research demonstrating that it is possible to train basic cognitive processes (EFs) that lead to relevant changes in complex cognitive tasks which are important for scholastic achievement (reading). However, the extent of transfer to cognitive domains after cognitive training is still heavily debated with meta-analyses showing consistent benefits to other EFs tasks, but with mixed findings to more complex tasks, such as reading (Pahor et al., 2018). Thus, we suggest that caution is exercised when comparing studies, since approaches to cognitive training vary broadly, and differences in trained populations are critical factors in analyzing potential learning and transfer. More studies which pursue the same goal are needed before we can arrive at firm conclusions on the role of cognitive training and its transfer potentials.

The main caveat of the present study is how SES was operationalized and assessed. We assumed for the purposes of the present study, based on previous sociodemographic data, that low-SES children would be in their majority in public school settings, and high-SES children would belong to private school settings. However, we are aware that this distribution is in fact a continuum, rather than a clear-cut categorization. Future studies should take a more analytical and, therefore, comprehensive view of SES, possibly using the score collected using specific socioeconomic scales (like the one designed by Lipina (2017)) as a continuous variable in the analysis, attributing to each participant a particular SES score.

Another limitation is the fact that in the present study improvement was assessed solely in terms of pre and posttests; that is, only immediate effects of 
cognitive training were included in the analysis. Further research should also look at the interplay between longitudinal effects and immediate effects, contrasting data provided by the follow-up tests to the data from post tests.

Overall, we hope that our study provides a tentative rationale for future work aiming at addressing whether targeted EF training might benefit children in regular school environments, specially those children from less privileged SES, who usually lag behind their more privileged SES peers. This would represent a gigantic step towards science for social justice in our country. In a broader perspective, we believe our study represents a contribution in providing psycholinguistic data to help support evidence-based education in Brazil.

Notes

1. This study was financed in part by the Coordenação de Aperfeiçoamento de Pessoal de Nível Superior - Brasil (CAPES) - Finance Code 001.

2. WEIRD stands for western, educated, industrialized, rich and democratic populations.

3. SES data were collected using a Socioeconomic Scale (NES), developed by Sebastian Lipina and collaborators in Argentina (Lipina, 2017). This scale considers numerous factors, such as parents' education and occupation levels, overcrowding, housing and sanitation conditions, etc. However, these data were not yet included in this paper and will be used in future publications.

4. Specifically in the Public School, even though children studied in the 3rd and 4th grades, some were 11 or older.

5. The data from the follow-up sessions were not included in this paper, since this phase of data collection was still in progress when the manuscript was submitted.

6. All the testing and training games were translated to Brazilian Portuguese by the staff at UCI's Working Memory and Plasticity Lab together with one of the Brazilian researchers.

7. Intervention games were developed at UCI - University of California - at the Working Memory and Plasticity Lab, under the supervision of Dr. Susanne Jaeggi.

\section{References}

Alloway, T., Gathercole, S., Kirkwood, H., \& Elliott, J. G. (2008). The cognitive and behavioral characteristics of children with low working memory. Child Development, 80, 606-621.

Au, J., Jaeggi, S. M., \&Buschkuehl, M. (2018). Effects of non-symbolic arithmetic training on symbolic arithmetic and the approximate number system. ActaPsychologica, 185, 1-12. https://doi.org/10.1016/j.actpsy.2018.01.005

Baddeley, A. D., \& Hitch, G. J. (1994). Developments in the concept of working memory. Neuropsychology 8:485-93.

Bowers, J. S. (2016). The practical and principled problems with educational neuroscience. Psychological Review,[s.1.], v. 123, n. 5, p.600-612. American Psychological Association (APA). http://dx.doi.org/10.1037/rev0000025.

Brickenkamp, R. (2002). Test d2. The d2 test of attention (9th ed.). Goettingen, Germany: Hogrefe.

Brito, N. H., \& Noble, K. G, (2014). Socioeconomic status and structural brain 
development. Frontiers in Neuroscience, 8, 1-12. https://doi.org/10.3389/ fnins.2014.00276

Chein, J. M., \& Morrison, A. B. (2010). Expanding the minds workspace: Training and transfer effects with a complex working memory span task. Psychonomic Bulletin \& Review, 17(2), 193-199.

Coltheart, M. (2013). Modelando a leitura: a abordagem da dupla rota. In: Snowling, M. J.; Hulme, C. A ciência da leitura. Porto Alegre: Penso. Cap. 1. p. 24-41.

Diamond, A. (2013). Executive Functions. Annual Review of Psychology, 64, 135-68.

Dresler, T., Bugden, S., Gouet, C., Lallier, M., Oliveira, D. G., Pinheiro-Chagas, P., Pires, A. C., Wang, Y., Zugarramurdi, C., \& Weissheimer, J. (2018). A Translational Framework of Educational Neuroscience in Learning Disorders. Frontiers in Integrative Neuroscience, v. 12, p. 25.

Duncan, G. J. and Magnuson, K. (2012). Socioeconomic Status and Cognitive Functioning: Moving from Correlation to Causation. Wiley Interdisciplinary Reviews: Cognitive Science, 3(3), 377-386.http://dx.doi.org/10.1002/wcs.1176

Farah, M. J. (2017). The Neuroscience of Socioeconomic Status: Correlates, Causes, and Consequences. Neuron 96, 56-71.

Farah M.J., Shera D.M., Savage J.H., Betancourt L., Giannetta J.M., Brodsky N.L., Malmud E.K., \& H, Hurt. (2006). Childhood poverty: Specific associations with neurocognitive development. Brain Research, 1110, 166-174.

Goldin A.P., Hermida M.J., Shalom D.E., Elias Costa M., Lopez-Rosenfeld M., Segretin M.S., Fernández-Slezak D., Lipina S.J., \& Sigman M. (2014). Far transfer to language and math of a short software-based gaming intervention. Proceedings of the National Academy of Sciences of the United States of America 111 (17): 64436448. http://dx.doi.org/10.1073/pnas.1320217111.

Hackman, D. A., \& Farah, M. J. (2009). Socioeconomic Status and the developing brain. Trends in Cognitive Sciences, 13, 65-73.http://dx.doi.org/10.1016/j. tics.2008.11.003.

Hofmann, W., Schmeichel, B. J., \& Baddeley, A. D. (2012). Executive functions and self-regulation. Trends in Cognitive Science, 16, 174-180.

Hsu, N. S., Novick, J. M., \& Jaeggi, S. M. (2014). The development and malleability of executive control abilities. Frontiers in Behavioral Neuroscience, 8, 1-15.

Jaeggi, S. M., Buschkuehl, M., Jonides, J., \& Perrig, W. J. (2008). Improving fluid intelligence with training on working memory. Proceedings of the National Academy of Sciences, 105(19), 6829-6833.

JASP Team (2019). JASP (Version 0.9) [Computer Software]. Retrieved from https:// jasp-stats.org/.

John A. M. St., Kibbe, M., \& Tarullo, A. R. (2019). A systematic assessment of socioeconomic status and executive functioning in early childhood. Journal of Experimental Child Psychology 178, 352-368.

Lent, R., Buchweitz, A., \&Mota, M. (2018). Ciência para Educação: Uma Ponte entre Dois Mundos. Rio de Janeiro: Atheneu.

Lipina, S. J. (2017). Critical considerations about the use of poverty measures in the study of cognitive development. International Journal of Psychology. Vol. 52, No. 3, 241-250.http://dx.doi.org/10.1002/ijop.12282.

Lipina, S. J., Martelli, M. I., Vuelta, B., \& Colombo, J. A. (2005). Performance on the A-not-B task of Argentinean infants from unsatisfied and satisfied basic needs homes. Interam. J. Psychol. 39, 49-60. 
Loosli S.V., Buschkuehl M., Perrig W.J., \& Jaeggi S.M. (2012). Working memory training improves reading processes in typically developing children. ChildNeuropsychology, 18:1, 62-78.

Maia, M. (2018). Psicolinguística e Educação. Campinas: Mercado de Letras, 258p.

Miyake A, Friedman N.P., Emerson M.J., Witzki A.H., Howerter A, \& Wager T.D. (2000). The unity and diversity of executive functions and their contributions to complex "frontal lobe" tasks: a latent variable analysis. Cogn. Psychol. 41:49-100.

Monsell, S. (2003) Task switching. Trends Cogn. Sci. 7, 134-140.

Noble, K. G., Norman, M. F., \& Farah, M. J. (2005). Neurocognitive correlates of socioeconomic status in kindergarten children. Developmental Science, 8, 74-87.

Noble, K. G., McCandliss, B. D., \& Farah, M. J. (2007). Socioeconomic Gradients Predict Individual Differences in Neurocognitive Abilities. Developmental Science, 10, 464-480. https://doi.org/10.1111/j.1467-7687.2007.00600.

Pahor, A., Jaeggi, S.M., \& Seitz, A. (2018). Brain Training. In: eLS. John Wiley \& Sons, Chichester.

Ramani, G. B., Jaeggi, S. M., Daubert, E., \& Buschkuehl, M. (2017). Domain-general and domain-specific training to improve kindergarten children's mathematics. JournalofNumericCognition, 3(2), 1-28.

Salles, J. (2005). Habilidades e dificuldades de leitura e escrita em crianças de $2^{\text {a }}$ série: abordagem neuropsicológica cognitiva (Doctoral dissertation). Retrieved from Programa de Pós-graduação em Psicologia do Desenvolvimento, Universidade Federal do Rio Grande do Sul.

Saraiva, R. A., Moojen, S. M. P. \& Munarski, R. (2007). Avaliação da Compreensão Leitora de Textos Expositivos. 2. ed. São Paulo: Casa do Psicólogo, 2009.

Sigman, M., Peña, M., Goldin, A.P., \&Ribeiro, S. (2014). Neuroscience and education: prime time to build the bridge. Nature Neuroscience, 17, 497-502. http://dx.doi. org/10.1038/nn.3672.

Varma, S., McCandliss, B. D., \& Schwartz, D. L. (2008). Scientific and Pragmatic Challenges for Bridging Education and Neuroscience. Educational Researcher, 37(3), 140-152. https://doi.org/10.3102/0013189X08317687.

Zhang, Q., Wang, C., Zhao, Q., Yang, L. Buschkuehl, M., \& Jaeggi, S. M. (2018). The malleability of executive function in early childhood: Effects of schooling and targeted training. Developmental Science. 1-15.

Recebido em: 10/03/2019

Aceito em: 25/07/2019 